\title{
MOLECULAR IDENTIFICATION OF CLINICAL MICROBES IN THALASSEMIA PATIENTS USING 16S rRNA GENE SEQUENCING
}

\author{
PISHTIWAN, A. H. ${ }^{*}$ - KHADIJA, KH. M. \\ Department of Biology, College of Education, Salahaddin University-Erbil, Iraq \\ *Corresponding author \\ e-mail: pishtiwan.hamad@su.edu.krd; phone: +964-750-462-6670 \\ (Received 28 $8^{\text {th }}$ May 2019; accepted $2^{\text {nd }}$ Sep 2019)
}

\begin{abstract}
Bacteria that are not identified by utilizing automated and manual systems can be identified precisely using $16 \mathrm{~S}$ rRNA gene sequencing. It can also be used to characterize previously undescribed species. In the present study, the experiment entailed 16S rRNA sequencing of bacteria isolated from thalassemia patients in Erbil, Iraq. Samples were obtained from thalassemia patients from different sources. The bacteria were first identified by biochemical and Vitek method, and finally, the 16S rRNA of 78 clinical bacteria were amplified by PCR and sequenced. The results of the sequencing methods performed on the clinical bacteria identified the isolates as 5 genera and 7 species: E. coli, P. aeruginosa, K. oxytoca, K. pneumoniae, M. morganii, E. fergusonii, and Pantoea sp. The results show that the most common causative organism was E. coli, and the most common site of infection was found to be the urinary tract. The results demonstrated the significance of 16S rRNA sequencing in accurate identification bacteria and understanding the bacterial diversity. Given the advantages of 16S rRNA sequencing method including cost-effectiveness, availability, and convenience, and it would be worthwhile to integrate it into clinical practice in developing countries.
\end{abstract}

Keywords: E. coli, microbial identification, VITEK 2, 16S rRNA gene, phylogenetic analysis

\section{Introduction}

As a severe genetic blood disorder that results from a mutation in the globin gene, thalassemia causes excessive destruction of red blood cells. Its prevalence has been reported to be high among populations in Southeast Asia, Africa, and the Mediterranean region. Given the severity of its clinical presentation, thalassemia syndrome has been classified into 3 subgroups: thalassemia minor, thalassemia intermediate, and thalassemia major. Patients with thalassemia major have been the focus of most studies of bacterial infections (Vichinsky, 2005; Weatherall, 2012). According to the estimations, Betathalassemia afflicts more than 42000 newborns every year all over the world. If the patients are not treated, for example through blood transfusion, Beta-thalassemia major (TM) causes the infected children to die before they are 3 years old (Modell and Darlison, 2008).

As major complications and the second most frequently reported cause of mortality, infections have been referred to as the main cause of death in patients with thalassemia. A range of immune abnormalities, splenectomy, iron overload, and severe anaemia are the predisposing factors for infection in patients with thalassemia. Yersinia enterocolitica in western countries and Klebsiella spp in Asia have been introduced as the major causative organisms of bacterial infections in thalassaemic patients (Vento et al., 2006). The most common bacterial infections in thalassaemic patients are liver abscesses, septicaemia, soft tissue infection, biliary tract infection, and pneumonia, while the most frequently isolated bacteria are reported to be Yersinia enterocolitica, Salmonella typhi, Streptococcus 
pneumoniae, Escherichia coli, Klebsiella pneumoniae, and other gram-negative bacteria (Aswapokee, 1988; Issaragrisil, 1988; Peng et al., 2000; Wanachiwanawin, 2000; Li et al., 2001; Chung et al., 2003; Wang et al., 2003). Yet, no studies have been carried out on bacterial infections in patients with thalassemia in the Kurdistan Region of Iraq.

Biochemical techniques and traditional culture are still the major methods in clinical microbiology laboratories to identify most pathogens. However, as technology has developed more than ever, many laboratories have adopted automated microbiology systems for the purpose of identifying pathogens. In recent years, there have been more reports on severe infections among patients. In most laboratories, the automated biochemical text platforms can be utilized to identify a number of clinical isolates from such patients. However, identifying some isolates is difficult through those platforms (Cheng et al., 2014). Currently, precise and fast identification of infectious agents is referred to as one of the main challenges for public health surveillance and clinical practice. Even the presence of a pathogen is usually vague in the setting of clinical syndromes like sepsis because causative agents are cultured in less than half of these cases (Martin et al., 2003), which leads to treating a large number of patients empirically. In addition, as indicated by several studies, patient outcomes, especially in the intensive care unit setting, can be significantly improved by appropriate, rapid, and adequate antibiotic treatments, moreover, it has been stated that patient mortality increases by 2 folds in the absence of such treatments (Iregui et al., 2002; Shorr et al., 2011). Therefore, molecular methods for bacterial identification are highly recommended.

Complete sequencing of the genome of some bacteria has been performed since automated DNA sequencing and polymerase chain reaction (PCR) were invented. As revealed by comparing the genomic sequences of bacterial species, the $16 \mathrm{~S}$ ribosomal RNA (rRNA) gene is strongly conserved within a species and among species of the same genus; therefore, it can be utilized as a novel gold standard for specifying bacteria (Woo et al., 2000). The $16 \mathrm{~S}$ rRNA gene sequences are very useful to study bacterial taxonomy and phylogeny. Over time, the function of the 16S rRNA gene has not changed despite the presence of the gene in almost all bacteria, often existing as a multigene family or operons, which suggests the fact that time is more accurately measured through random sequence changes, and the $16 \mathrm{~S}$ rRNA gene (1500 bp) is large enough for informatic purposes (Patel, 2001). It has been stated that applying molecular approaches for clinical diagnosis has numerous advantages, including ease of specimen processing, speed, and sensitivity, over standard microbiological techniques. This has been proved to be useful to identify both fastidious, unusual and slow-growing bacteria and rare bacteria that have ambiguous profiles, which cannot be differentiated correctly by conventional methods (Sun et al., 2005; El Bakkali et al., 2013).

The present study was carried out in order to identify gram-negative bacteria in patients with thalassemia by employing 16S-rRNA gene sequencing and to compare $16 \mathrm{~S}$ rRNA gene sequencing and non-16S based clinical methods (automated and phenotypic identification methods) regarding their identification accuracy.

\section{Materials and methods}

\section{Clinical isolates}

Specimens were retrieved form 160 thalassemia patients (85 females and 75 males) who referred to thalassemia center in Erbil province, Iraq. The records of total patients were reviewed, and bacterial infections were observed in 78 patients $(48.75 \%)$. The 78 
isolates were collected in various sources: urine cultures, buccal cavity specimens, ear specimens, and blood cultures over two years period from June 2016 to September 2018. In general, the isolates were represented the most common Gram-negative bacterial pathogens.

\section{Culture-based and automated identification of clinical isolates}

The isolates that were obtained from the thalassemia center had undergone culture and sub-culture on relevant selective media, which include MacConkey agar, Eosin methylene blue agar, Cetrimide agar and Xylose lysine deoxycholate. Afterwards, in order to provide a final culture-based identification, clinical microbiology laboratory protocols were utilized to test their biochemical profile (Collee et al., 1996; Atlas, 2010). Then, the isolates identified by automated microbiology system using the VITEK2 compact system (BioMerieux, France).

\section{S rRNA-based molecular identification of clinical isolates}

The full length of 16S rRNA of all 78 bacterial strains was sequenced. From those 78 isolates, some bacteria had not been identified clearly by VITEK2 method or phenotypic methods. Therefore, 16S rRNA sequencing was utilized to identify the bacterial isolates with high confidence.

\section{Genomic DNA preparation}

Presto $^{\mathrm{TM}}$ Mini gDNA bacterial kit was used to isolate genomic DNA. The samples were stained with safe stain and run on $0.8 \%$ agarose gel. The presence of genomic bands in the gel was examined under UV light (Fig. 1). The DNA was stored at $-20^{\circ} \mathrm{C}$ until it was used for the PCR amplification.

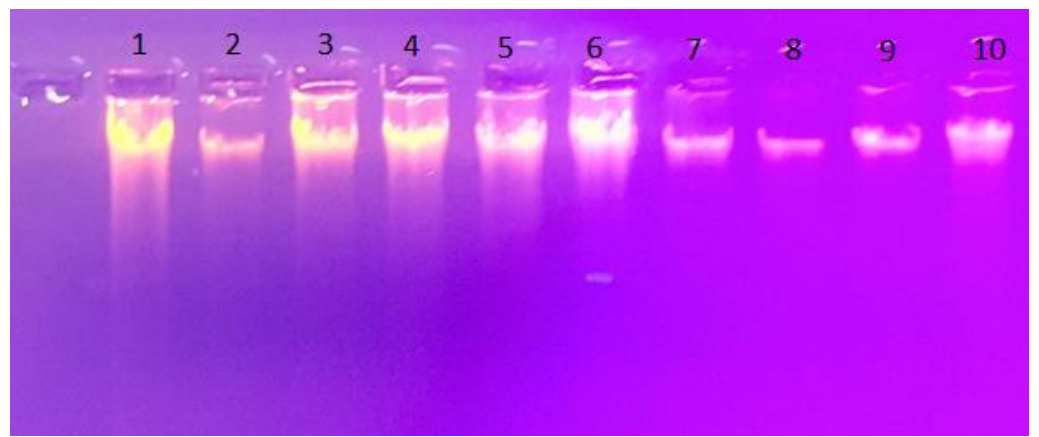

Figure 1. Bacterial genome of 10 isolates in agarose gel electrophoresis

\section{Amplification of $16 S$ gene}

Universal primers 1492R (1) (5'- GGTTACCTTGTTACGACTT -3') as reverse primer and 8F (5'- AGAGTTTGATCCTGGCTCAG -3') as forward were used to carry out PCR for the amplification of the 16S rRNA gene (Turner et al., 1999). All reactions of PCR were conducted by utilizing $2 \mu \mathrm{l}$ DNA template (density of $10 \mathrm{ng} / \mu \mathrm{l}$ ), the Master Mix consisting of $3 \mathrm{mM} \mathrm{MgCl} 2,0.2 \%$ Tween ${ }^{\circledR} 20,20 \mathrm{mM}$ Tris- $\mathrm{HCl} \mathrm{pH} 8.5$, $\left(\mathrm{NH}_{4}\right) 2 \mathrm{~S}_{4}, 0.2$ units/ $\mu 1$ Ampliqon Taq DNA polymerase, $0.4 \mu \mathrm{M}$ of each primer, and $0.4 \mathrm{mM}$ of each $\mathrm{dNTP}$. The conditions of PCR included primary denaturation at $95{ }^{\circ} \mathrm{C}$ 
for $5 \mathrm{~min}$, followed by 35 cycles at $95{ }^{\circ} \mathrm{C}$ for $45 \mathrm{~s}$, at $55{ }^{\circ} \mathrm{C}$ for $45 \mathrm{~s}$, and at $72{ }^{\circ} \mathrm{C}$ for $90 \mathrm{~s}$, and a last extension at $72{ }^{\circ} \mathrm{C}$ for $6 \mathrm{~min}$. After safe staining, the product of the reaction was visualized under UV light on a 1\% agarose gel (Sambrook et al., 2001; Fig. 2). The PCR products were used for sequencing the $16 \mathrm{~S}$ rRNA of all 78 bacterial isolates.

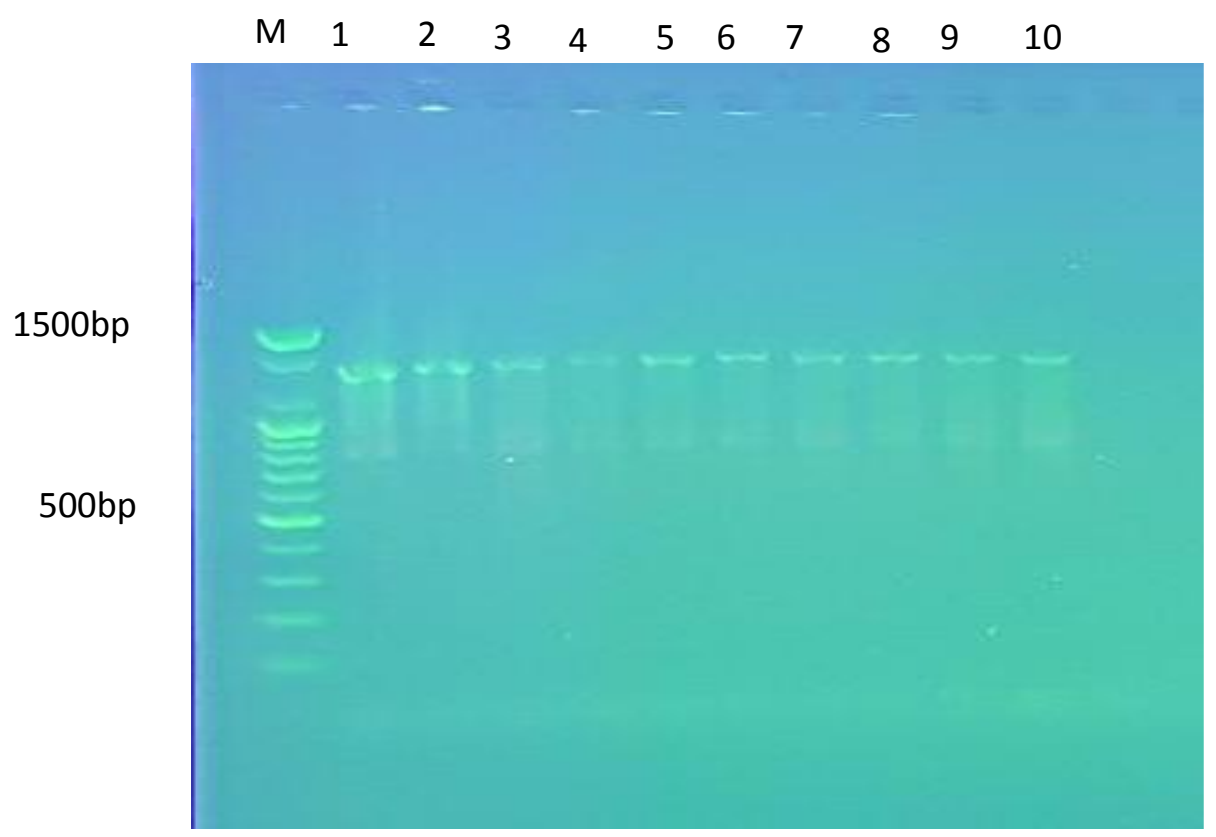

Figure 2. Bacterial 16S rRNA PCR products in agarose gel electrophoresis

\section{Phylogenetic analysis and sequencing of 16S rRNA gene}

The automated sequencer ABI 3100 with Big Dye Terminator Kit v. 3.1 was utilized to purify and sequence the amplified PCR products of microbial gene fragments at MACROGEN, Seoul, Korea. Primers 1391R (5' - GACGGGCGGTGTGTRCA -3') was used for sequencing (Turner et al., 1999). Sequencing was performed in only one direction since this is easy and inexpensive and phylogenic analysis is reported to be insensitive to quality of sequencing. As a result, the obtained sequences were compared with the database of NCBI via BLAST searches (http://blast.ncbi.nlm.nih.gov/Blast.cgi). In this comparison, sequences of type strains most closely related to the sequences of the isolates were searched. The sequences in the present study were only blasted against full genome sequences in NCBI database. For the phylogenetic analysis, the obtained sequences were aligned with Clustal $\mathrm{W}$, and method based on the Jukes-Cantor model using the software MEGA and by the Maximum Likelihood, evolutionary distances were used to construct a phylogenetic tree (Kumar et al., 2016; Jukes and Cantor, 1969).

\section{Results}

In the current study, a total of 160 patients (85 females, 75 males) who referred to thalassemia center in Erbil, Iraq were examined, and 78 patients $(48.75 \%)$ were found to suffer from bacterial infections. From these patients, 78 isolates were collected from 
various sources: urine cultures, buccal cavity specimens, ear specimens, and blood cultures over a over two years period from June 2016 to September 2018. The isolates were initially been identified using either conventional (which is depend on cultural, morphological, and biochemical tests) or by automated microbiology system using the VITEK 2 compact system. These initial identities span 5 genera and 2 families, including a wide range of gram-negative rods. Among the 78 gram-negative isolates, 77 $(98.7 \%)$ were members of Enterobacteriaceae and 1 (1.3\%) members of Pseudomonadaceae.

Out of those 78 patients with infections, the most common causative organism was found to be $E$. coli $(\mathrm{n}=48,61.53 \%)$, followed by $K$. pneumoniae $(\mathrm{n}=14,17.94 \%), M$. morganii $(\mathrm{n}=11,14.10 \%), K$. oxytoca $(\mathrm{n}=3,3.84 \%)$, and $P$. aeruginosa and Pantoea sp. $(\mathrm{n}=1, \% 1.28)$. Moreover, urinary tract infection was the most common site of infection $(\mathrm{n}=61,78.20 \%)$, followed by oral cavity infection $(\mathrm{n}=10,12.82 \%)$, ear otitis media $(\mathrm{n}=5,6.41 \%)$, and blood bacteremia $(\mathrm{n}=2,2.56 \%)$. Tables 1 and 2 summarize the causative organisms, number of isolates, clinical identification method, and sites of infection in the 78 infected patients.

Table 1. Clinical identity and techniques of identifying the isolates

\begin{tabular}{c|c|c}
\hline Clinical identity & Identification technique & Number of isolates (\%) \\
\hline Escherichia coli & Culture-based + VITEK 2 compact system & $48(61.53)$ \\
Klebsiella pneumonia & Culture-based + VITEK 2 compact system & $14(17.94)$ \\
Morganella morganii & VITEK 2 compact system & $11(14.10)$ \\
Klebsiella oxytoca & Culture-based + VITEK 2 compact system & $3(3.84)$ \\
Pseudomonas aeruginosa & Culture-based + VITEK 2 compact system & $1(1.28)$ \\
Pantoea species & VITEK 2 compact system & $1(1.28)$ \\
\hline
\end{tabular}

Table 2. Sites of infection

\begin{tabular}{c|c}
\hline Site of infection, $\mathbf{n}(\boldsymbol{\%})$ & Patients $(\mathbf{n}=\mathbf{7 8})$ \\
\hline Urine urinary tract infection & $61(78.20)$ \\
Oral cavity & $10(12.82)$ \\
Ear Otitis media & $5(6.41)$ \\
Blood Bacteremia & $2(2.56)$ \\
\hline
\end{tabular}

After isolates had initially been identified using either conventional or by automated microbiology system using the VITEK 2 compact system, the molecular method was used for isolate identification based on the sequence of $16 \mathrm{~S}$ ribosomal RNA. The $16 \mathrm{~S}$ rRNA gene was amplified and sequenced for each strain to confidently identify bacteria. Out of the 77 members of Enterobacteriaceae, 48 (62.3\%) were confirmed as E. coli by conventional and automated microbiology system using the VITEK 2 compact system, whereas $16 \mathrm{~S}$ rRNA sequencing method confirmed only 41 isolates as E. coli. Regarding the other Escherichia isolates, 5 out of the 48 tested isolates were sequenced successfully, but their sequences did not match with high similarity to any known bacterial deposited in NCBI database; therefore, they were called as unidentified bacteria since they had similarity with unknown cultured bacteria in the database. 
Interestingly, the 2 Escherichia isolates without species ID were identified as $E$. fergusonii and $M$. morganii by $16 \mathrm{~S}$ rRNA sequencing.

In general, the $16 \mathrm{~S}$ rRNA gene is universal in bacteria, and so relationships can be measured among all bacteria. The comparison of the 16S rRNA gene sequences allows differentiation between organisms at the genus level across all major phyla of bacteria, in addition to classifying strains at multiple levels, including what we now call the species and subspecies level. The occasional exceptions to the usefulness of $16 \mathrm{~S}$ rRNA gene sequencing usually relate to more than one well-known species having the same or very similar sequences.

Regarding Klebsiella species, among the 17 isolates, 14 isolates were confirmed as Klebsiella pneumoniae and 3 as Klebsiella oxytoca by conventional and automated microbiology system using the VITEK 2 compact system, while 16S rRNA sequencing method revealed $11 \mathrm{~K}$. pneumoniae isolates and $4 \mathrm{~K}$. oxytoca 4 isolates. Moreover, 11 member of non-lactose fermenter that identified by conventional and automated method as Morganella morganii, this ratio rose to $14 \mathrm{M}$. morganii by $16 \mathrm{~S}$ rRNA sequencing method. One isolate that was identified by automated method as Pantoea species was confirmed by molecular method too. On the other hand, one members of Pseudomonadaceae was Pseudomonas aeruginosa that was identified by conventional and automated methods and confirmed by molecular methods.

Table 3 presents the results of comparing conventional and automated identification methods with the molecular approach is shown in. As shown in the table, 58 (74.35) out of 78 isolates were correctly identified.

Table 3. Comparison between conventional and automated methods with the molecular approach

\begin{tabular}{c|c|c}
\hline \multirow{2}{*}{ Isolates } & \multicolumn{2}{|c}{ Clinical identification } \\
\cline { 2 - 3 } & Conventional and automated & 16S rRNA \\
\hline E. coli & 48 & 41 \\
K. pneumoniae & 14 & 11 \\
M. morganii & 11 & 14 \\
K. oxytoca & 3 & 4 \\
P. aeruginosa & 1 & 1 \\
Pantoea species & 1 & 1 \\
E. fergusonii & 0 & 1 \\
Unidentified & 0 & 5 \\
Total & 78 & 78 \\
\hline
\end{tabular}

Furthermore, the Neighbour-joining method was utilized to draw phylogenetic trees for $16 \mathrm{~S}$ rRNA region. Moreover, MEGA (Molecular Evolutionary Genetics analysis) version 7.0 was employed to perform the molecular and phylogenetic evolutionary analyses. In addition, nucleotide BLAST was utilized to compare different sets of sequence databases and the $16 \mathrm{~S}$ rRNA gene sequence of isolate. Bacterial identification was conducted using the annotated information for the sequence in the database of whole-genome sequences to which $16 \mathrm{~S}$ rRNA aligns.

Phylogenetic tree of E. coli is presented in Figure 3A, which was drawn based on 1,548 conserved core gene clusters of $41 \mathrm{E}$. coli genomes. The phylogenetic trees 
clearly indicate that there was an intra-species genetic distance of 0.010 between the individual isolates. As shown in Figure 3B; however, there was an intra-species genetic distance of 0.0020 between the individual isolates of the 11 Klebsiella pneumoniae. Moreover, in Figure 3C, an intra-species genetic distance of up to 0.020 was observed between the individual isolates of the Morganella morganii. Based on these findings, compared to E. coli and Klebsiella pneumoniae, Morganella morganii had a higher rate of evolution and the genetic variation.
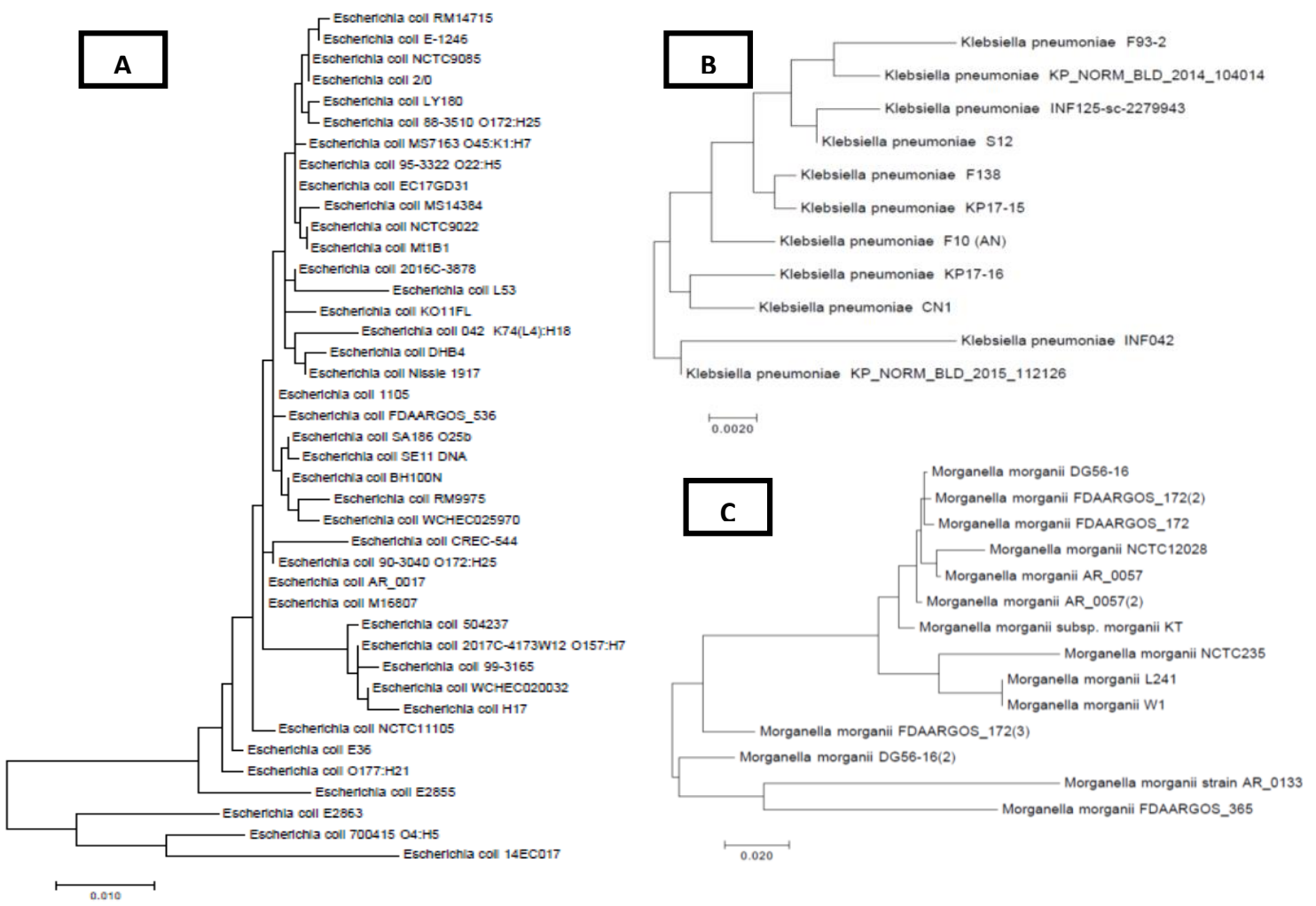

Figure 1. Phylogenetic neighbor-joining trees of $16 S \mathrm{r}$ RNA amplified from the tested isolates of E coli (A), K. pneumoniae (B), and M. morganii (C)

\section{Discussion}

Most of the isolates in the present study were identified by an automated microbiology system (i.e. BioMerieux VITEK 2 Compact) and conventional phenotypic method. However, the $16 \mathrm{~S}$ rRNA gene was sequenced and amplified for each strain in order to identify the bacteria confidently. In scientific investigations and clinical practice, identification of bacterial species is frequently performed through sequence analysis of conserved "housekeeping" genes like the bacterial 16S rRNA (Clarridge, 2004; Petti et al., 2005). In fact, Bacterial identification traditionally achieved by carrying out labor-intensive and time-consuming, and the interests of identification genotypically are many including shorter time for results, higher reliability, sensitivity, and specificity (Jesumirhewe et al., 2016). To specify the phylogenetic characterization of prokaryotes such as archaea and bacteria, the $16 \mathrm{~S}$ rRNA gene sequence is utilized as the template in the latest bacteria identification manuals such as Bergey's Manual of Systematic Bacteriology which is widely used by microbiologists to identify and characterize bacteria (Werner et al., 2012). 
In order to identify previous bacteria in clinical settings and amplify $16 \mathrm{~S}$ rRNA, a set of universal reference primers were chosen based on previous clinical work and key reports. Moreover, previously conducted taxonomic studies have utilized sequence analysis of the $16 \mathrm{~S}$ ribosomal RNA (rRNA) gene in order to identify bacterial species (Chakravorty et al., 2007).

Identifying typical clinical isolates through PCR and sequencing in the present study revealed the fact the consistency of this method with conventional laboratory methods. The desirable characteristics of this molecular identification method include: (1) costeffectiveness: Given the low cost of developing the technology and information, the procedure is quite cost-effective; (2) accessibility: this procedure has a high level of accessibility because it is developed based on well-established methods and theories such as amplicon preparation through PCR, commercial sequencing, and Gene Bank verification); and (3) convenience: This procedure is quite convenient because it utilizes common techniques and methods of molecular biology including sequence analysis, commercial sequencing, electrophoresisand, PCR, and efficient one-step DNA extraction. Identifying microbes that are difficult to identify is conducted using molecular methods if laboratories do not have the required expertise to use other phenotypic identification methods (Cheng et al., 2014). Although 16S rRNA gene sequencing is frequently utilized in reference laboratories, the difficulty of interpreting $16 \mathrm{~S}$ rRNA gene sequence results is one of the main limitations to its broader use. Marginal intra-species differences and significant inter-species differences in 16S rRNA gene sequences have a remarkable effect on utilizing $16 \mathrm{~S}$ rRNA gene sequencing to identify bacteria. As a result, identifying the bacteria cannot be done with sufficient confidence through this technique when the same 16S rRNA gene sequence is share by two different bacterial species (Woo et al., 2009).

In the present study, sequencing was used to identify different bacteria. It was observed that sequence analysis had an excellent overall performance in distinguishing the bacterial isolates that were difficult to identify. Therefore, bacteria identification in clinical settings can be aided by the $16 \mathrm{~S}$ rRNA sequencing as a supplement, particularly for organisms that are biochemically fastidious or deficient or poorly described. Pantoea is a difficult-to-identify bacterium. This bacterium can lead to development of infections in humans. It is also pathogenic to plants. However, different strains of Pantoea and their probable association with disease and hosts are poorly known, and it is difficult to identify Pantoea species. The biochemical heterogeneity of Pantoea makes it to be identified difficulty and due to similarities in phenotypic characteristics between Pantoea species and related Enterobacteriaceae. Currently, confident identification is not achieved routinely (Delétoile et al., 2009; Brady, 2013).

The advantage of $16 \mathrm{~S}$ rRNA gene sequencing in clinical microbiology has been focused on in several studies. For example, Drancourt et al. (2000) carried out a study to compare 16S rRNA and phenotypic based identification techniques. For this purpose, they obtained 177 isolates, 81 of which were collected from medical clinical samples. Also, Bosshard et al. (2003) assessed the appropriateness of 16S rRNA for the identifying the clinical strains of aerobic gram-positive rods. Moreover, Spilker et al. (2004) examined 66 cystic fibrosis sputum isolates in order to check the agreement between the results identification of Pseudomonas species using phenotypic and $16 \mathrm{~S}$ rRNA sequencing methods.

The present investigation, 78 infected patients were studied to figure out the causative organisms and sites of infection. It was observed that the most common 
causative organism was E. coli that was identified in 41 cases, followed by Morganella morganii with 14 cases and $K$. pneumoniae with 11 cases. Moreover, the most common site of infection was identified to be urinary tract infection with 61 cases, followed by oral cavity infection with 10 cases.

The profile of pathogens in the series of the present study differed from those that were previously described for thalassaemia, such that Escherichia coli was the most common causative organism, followed by Morganella morganii in the second place and Klebsiella species in the third place. This finding is in line with those two studies that were conducted on Asian patients with thalassemia (Wang et al., 2003; Yapp et al., 2009). However, this finding is not in agreement with those of the studies conducted in Western countries, where the most common causative organism in thalassemia patients was found to be Yersinia species (Robins-Browne and Prpic, 1985; Abcarian and Demas, 1991).

In the present study, Escherichia coli species were found to be the most frequent organisms that cause infection in thalassemia, which can probably be contributed to the fact that there were a larger number of female patients than the males and that women develop urinary tract infections four times more frequently than males, and it is well known that Escherichia coli bacteria are responsible for most cases of urinary tract infection (UTI) (Sakamoto et al., 2018; Alperin et al., 2019).

In the present study, excess iron presence might be the reason for different spectrum of infections among the patients. Moreover, since iron plays a role in the growth of Klebsiella spp., high levels of ferritin seem to be a risk factor (Chung et al., 2003). Dissemination and replication of bacterial pathogens in which iron is used as a growth factor can be promoted by high levels of serum iron. Saturation of transferrin in iron overload makes labile iron available to bacteria. Iron overload changes the phagocytic and chemotactic properties of neutrophils, in turn leading to a decrease in their capability of killing invading pathogens. It also seems to change the function of T-cell. Moreover, immune effector mechanisms like immune cell proliferation iron, nitric oxide (NO) formation, or cytokine activities (interferon-c effector pathways towards macrophages) are also modulated by iron (Hoen, 1999; Weiss, 2002; Wiener, 2003). Pseudomonas aeruginosa, Klebsiella species (e.g., pneumoniae), and Escherichia coli, which are gram-negative, rod-shaped bacteria, frequently lead to infections and mortality in a splenic patients (Cappellini et al., 2014).

\section{Conclusion}

The results of the current study indicated that using DNA sequencing techniques to identify bacteria isolates, especially biochemically aberrant, rarely isolated, or poorly described strains, in clinical settings can lead to remarkable improvement in clinical microbiology. It was found that accurate identification and understanding of bacterial diversity across and within the group were fulfilled through 16S-rRNA gene sequencing. In addition, low cost and high accuracy are guaranteed by sequencing technologies which are effective and appropriate for small- and medium-sized microbiological laboratories. Furthermore, the results of the present study revealed that identification of all cases is possible through single-strand sequencing. By studying the isolates obtained from thalassemia patients in the present study, it was concluded that genetic methods can help to identify the pathogenic isolates, which will be further helpful in administering appropriate antibiotics and understanding the trend of 
pathogens in various clinical samples. As figured out in the present study, the most common causative organisms were found to be Escherichia coli, followed by Morganella morganii While Klebsiella pneumoniae as the second and third most frequent causative organisms. It is recommended to depend on Multilocus Gene Sequencing for more rapid and accurate identification, especially for Pantoea typing in clinical samples due to its difficulty identification.

\section{REFERENCES}

[1] Abcarian, P. W., Demas, B. E. (1991): Systemic Yersinia enterocolitica infection associated with iron overload and deferoxamine therapy. - AJR. American Journal of Roentgenology 157: 773-775.

[2] Alperin, M., Burnett, L., Lukacz, E., Brubaker, L. (2019): The mysteries of menopause and urogynecologic health: clinical and scientific gaps. - Menopause 26: 103-111.

[3] Aswapokee, P. (1988): Severe infection in thalassemia: a prospective study. - Birth Defects 23: 521-526.

[4] Atlas, R. (2010): Handbook of Microbiological Media. 4th Ed. - ASM Press, Washington.

[5] Bosshard, P., Abels, S., Zbinden, R., Böttger, E., Altwegg, M. (2003): Ribosomal DNA sequencing for identification of aerobic gram-positive rods in the clinical laboratory (an 18-month evaluation). - Journal of Clinical Microbiology 41: 4134-4140.

[6] Brady, C. L. (2013): Taxonomic of Pantoea Associated with Bacterial Blight of Eucalyptus. - University of Pretoria, Hatfield.

[7] Cappellini, M., Cohen, A., Eleftheriou, A., Piga, A., Porter, J., Taher, A. (2014): Guidelines for the Clinical Management of Thalassaemia. - Thalassaemia International Federation (TIF), Strovolos, Cyprus.

[8] Chakravorty, S., Helb, D., Burday, M., Connell, N., Alland, D. (2007): A detailed analysis of $16 \mathrm{~S}$ ribosomal RNA gene segments for the diagnosis of pathogenic bacteria. Journal of Microbiological Methods 69: 330-339.

[9] Cheng, C., Sun, J., Zheng, F., Wu, K., Rui, Y. (2014): Molecular identification of clinical "difficult-to-identify" microbes from sequencing 16S ribosomal DNA and internal transcribed spacer 2. - Annals of Clinical Microbiology and Antimicrobials 13: 1.

[10] Chung, B. H., Ha, S. Y., Chan, G. C., Chiang, A., Lee, T. L., Ho, H. K., Lee, C. Y., Luk, C. W., Lau, Y. L. (2003): Klebsiella infection in patients with thalassemia. - Clinical Infectious Diseases 36: 575-579.

[11] Clarridge, J. E. (2004): Impact of 16S rRNA gene sequence analysis for identification of bacteria on clinical microbiology and infectious diseases. - Clinical Microbiology Reviews 17: 840-862.

[12] Collee, J. G., Miles, R. S., Watt, B. (1996): Tests for the Identification of Bacteria. - In: Collee, J. G., Fraser, A. G., Marmion, B. P., Simmons, A. (eds.) Mackie and McCartney Practical Medical Microbiology. 14th Ed. Churchill Livingstone, New York.

[13] Delétoile, A., Decré, D., Courant, S., Passet, V., Audo, J., Grimont, P., Arlet, G., Brisse, S. (2009): Phylogeny and identification of Pantoea species and typing of Pantoea agglomerans strains by multilocus gene sequencing. - Journal of Clinical Microbiology 47: 300-310.

[14] Drancourt, M., Bollet, C., Carlioz, A., Martelin, R., Gayral, J.-P., Raoult, D. (2000): 16S ribosomal DNA sequence analysis of a large collection of environmental and clinical unidentifiable bacterial isolates. - Journal of Clinical Microbiology 38: 3623-3630.

[15] El Bakkali, M., Chaoui, I., Zouhdi, M., Melloul, M., Arakrak, A., Elfahime, E., El Mzibri, M., Laglaoui, A. (2013): Comparison of the conventional technique and 16s 
rDNA gene sequencing method in identification of clinical and hospital environmental isolates in Morocco. - African Journal of Microbiology Research 7: 5637-5644.

[16] Hoen, B. (1999): Iron and infection: clinical experience. - American Journal of Kidney Diseases 34: s30-s34.

[17] Iregui, M., Ward, S., Sherman, G., Fraser, V. J., Kollef, M. H. (2002): Clinical importance of delays in the initiation of appropriate antibiotic treatment for ventilatorassociated pneumonia. - Chest 122: 262-268.

[18] Issaragrisil, S. (1988): Infection in thalassemia: a retrospective study of 1,018 patients with $\beta$-thalassemia/Hb E. - Birth Defects Orig Artic Ser 23: 505-511.

[19] Jesumirhewe, C., Ogunlowo, P. O., Olley, M., Springer, B., Allerberger, F., Ruppitsch, W. (2016): Accuracy of conventional identification methods used for Enterobacteriaceae isolates in three Nigerian hospitals. - PeerJ 4: e2511.

[20] Jukes, T. H., Cantor, C. R. (1969): Evolution of protein molecules. Mammalian protein Metabolism 3: 132.

[21] Kumar, S., Stecher, G., Tamura, K. (2016): MEGA7: molecular evolutionary genetics analysis version 7.0 for bigger datasets. - Molecular Biology and Evolution 33: 18701874.

[22] Li, C. K., Shing, M. M. K., Chik, K. W., Lee, V., Pan, P. M. (2001): Klebsiella pneumoniae meningitis in thalassemia major patients. - Pediatric Hematology and Oncology 18: 229-232.

[23] Martin, G. S., Mannino, D. M., Eaton, S., Moss, M. (2003): The epidemiology of sepsis in the United States from 1979 through 2000. - New England Journal of Medicine 348: 1546-1554.

[24] Modell, B., Darlison, M. (2008): Global epidemiology of haemoglobin disorders and derived service indicators. - Bulletin of the World Health Organization 86: 480-487.

[25] Patel, J. B. (2001): 16S rRNA gene sequencing for bacterial pathogen identification in the clinical laboratory. - Molecular Diagnosis 6: 313-321.

[26] Peng, C.-T., Tsai, C.-H., Wang, J.-H., Chiu, C.-F., Chow, K.-C. (2000): Bacterial infection in patients with transfusion-dependent beta-thalassemia in central Taiwan. Acta Paediatrica Taiwanica (Taiwan er ke yi xue hui za zhi) 41: 318-321.

[27] Petti, C., Polage, C., Schreckenberger, P. (2005): The role of 16S rRNA gene sequencing in identification of microorganisms misidentified by conventional methods. - Journal of Clinical Microbiology 43: 6123-6125.

[28] Robins-Browne, R., PRPIC, J. (1985): Effects of iron and desferrioxamine on infections with Yersinia enterocolitica. - Infection and Immunity 47: 774-779.

[29] Sakamoto, S., Miyazawa, K., Yasui, T., Iguchi, T., Fujita, M., Nishimatsu, H., Masaki, T., Hasegawa, T., Hibi, H., Arakawa, T. (2018): Chronological changes in the epidemiological characteristics of upper urinary tract urolithiasis in Japan. - International Journal of Urology 25: 373-378.

[30] Sambrook, J., Russell, D. W., Russell, D. W. (2001): Molecular Cloning: A Laboratory Manual. - Cold Spring Harbor Laboratory Press, New York.

[31] Shorr, A. F., Micek, S. T., Welch, E. C., Doherty, J. A., Reichley, R. M., Kollef, M. H. (2011): Inappropriate antibiotic therapy in Gram-negative sepsis increases hospital length of stay. - Critical Care Medicine 39: 46-51.

[32] Spilker, T., Coenye, T., Vandamme, P., Lipuma, J. J. (2004): PCR-based assay for differentiation of Pseudomonas aeruginosa from other Pseudomonas species recovered from cystic fibrosis patients. - Journal of Clinical Microbiology 42: 2074-2079.

[33] Sun, C.-P., Liao, J. C., Zhang, Y.-H., Gau, V., Mastali, M., Babbitt, J. T., Grundfest, W. S., Churchill, B. M., Mccabe, E. R., Haake, D. A. (2005): Rapid, species-specific detection of uropathogen 16S rDNA and rRNA at ambient temperature by dot-blot hybridization and an electrochemical sensor array. - Molecular Genetics and Metabolism 84: 90-99. 
[34] Turner, S., Pryer, K. M., Miao, V. P., Palmer, J. D. (1999): Investigating deep phylogenetic relationships among cyanobacteria and plastids by small subunit rRNA sequence analysis 1. - Journal of Eukaryotic Microbiology 46: 327-338.

[35] Vento, S., Cainelli, F., Cesario, F. (2006): Infections and thalassaemia. - The Lancet Infectious Diseases 6: 226-233.

[36] Vichinsky, E. P. (2005): Changing patterns of thalassemia worldwide. - Annals of the New York Academy of Sciences 1054: 18-24.

[37] Wanachiwanawin, W. (2000): Infections in E/b-thalassaemia. - Journal of Pediatric Hematology Oncology 22: 581-587.

[38] Wang, S.-C., Lin, K.-H., Chern, J. P., Lu, M.-Y., Jou, S.-T., Lin, D.-T., Lin, K.-S. (2003): Severe bacterial infection in transfusion-dependent patients with thalassemia major. Clinical Infectious Diseases 37: 984-988.

[39] Weatherall, D. J. (2012): The definition and epidemiology of non-transfusion-dependent thalassemia. - Blood Reviews 26: S3-S6.

[40] Weiss, G. (2002): Iron and immunity: a double-edged sword. - European Journal of Clinical Investigation 32: 70-78.

[41] Werner, J. J., Koren, O., Hugenholtz, P., Desantis, T. Z., Walters, W. A., Caporaso, J. G., Angenent, L. T., Knight, R., Ley, R. E. (2012): Impact of training sets on classification of high-throughput bacterial 16s rRNA gene surveys. - The ISME Journal 6: 94.

[42] Wiener, E. (2003): Impaired phagocyte antibacterial effector functions in $\beta$-thalassemia: a likely factor in the increased susceptibility to bacterial infections. - Hematology 8: 35-40.

[43] Woo, P., Leung, P., Leung, K., Yuen, K. (2000): Identification by $16 \mathrm{~S}$ ribosomal RNA gene sequencing of an Enterobacteriaceae species from a bone marrow transplant recipient. - Molecular Pathology 53: 211-215.

[44] Woo, P. C., Teng, J. L., Wu, J. K., Leung, F. P., Tse, H., Fung, A. M., Lau, S. K., Yuen, K.-Y. (2009): Guidelines for interpretation of 16S rRNA gene sequence-based results for identification of medically important aerobic Gram-positive bacteria. - Journal of Medical Microbiology 58: 1030-1036.

Yapp, A. R., Lindemann, R., Gilroy, N., Gao, Z., MacIntyre, C. R. (2009): Infection outcomes in splenectomized patients with hemoglobinopathies in Australia. International Journal of Infection Disease 13: 696-700. 